studies, which may well herald the advent of biophysics as the leading discipline in future experimental philosophy.

The chapters of this admirable book, each one by an acknowledged authority on his own ground, are written to survey a wide field: reminiscent, biographical, epistemological, psychological, and experiential. The late Dr. Alfred Schutz, one of the contributors, met Edmund Husserl many times during the nineteen-thirties in Freiburg, Vienna, or Prague, and sums up the impression that was universal, when the name of the master of phenomenology was mentioned, in just two words, "Ecce philosophus".

F. I. G. RAWLINS

\section{PRODUCTION AND PROCESSING OF URANIUM}

Uranium Production Technology

Edited by C. D. Harrington and A. E. Ruehle. Pp. xii +579. (Princeton, N.J., and London: D. Van Nostrand Company, Inc., 1959.) 131s. 6d. net.

THIS book is the first comprehensive compilation of the technology of uranium production. The material for the book was prepared by the technical personnel of the Uranium Division of Mallinckrodt Chemical Works, under the direction and guidance of the United States Atomic Energy Commission's Division of Information Services. The Commission recently declassified virtually all the significant features of the technology, thus making possible the publication of the book.

For the benefit of the industrial chemist, the production of pure uranium from the ore concentrate is described in considerable detail both in regard to the plant and to the chemistry of the processes involved. Plant for both batch and continuous processes is described, and the accounts of advanced methods, such as ion exchange and fluidized bed techniques for the manufacture of both uranium tetrafluoride and hexafluoride, are of special interest. It is apparent that very little information has been withheld, and cost figures for many of the processes are included.

For the metallurgist and the engineer there are excellent chapters dealing with the vacuum casting and subsequent forming of the uranium metal, and again considerable detail of the plant is given.

Chapter 10 is worthy of special mention and deals with the physical metallurgy of uranium related directly to the problems of metal production and fabrication. The structure in terms of the allotropic forms of uranium, the response to heat treatment and the degree to which the grain size may be controlled are all discussed. Lists of the usual mechanical properties, showing the effect of temperature, are given, and the final section reviews mechanisms of alloy formation and shows the effects of additions on the physical properties, structure and mechanical properties. The photomicrographs showing the structure of uranium and of typical inclusions are particularly useful.

British experience of fabricating uranium metal by methods other than casting and machining is relatively limited. The next three chapters, dealing with forging, extrusion and rolling, might therefore have been expected to be of especial interest. In fact they are just a little disappointing - particularly that on extrusion-and it is difficult to believe that we are being given an adequate account of the fairly extensive body of American knowledge on these aspects. An additional chapter on fabricating highuranium alloys gives some useful basic data; this chapter also has a very good bibliography.

The final chapter is devoted to health hazard control and gives an extensive review of this particularly important aspect of uranium processing. Shielding against beta and gamma radiation is described, and useful guidance on the methods available for dust control is given.

Few criticisms can be made of the book, and these are mainly minor ones. Its pages include a wealth of information on uranium production and processing. Extensive use is made of diagrams and photographs, and there are 750 references. The book will be invaluable to all those interested in the manufacturing processes of uranium and its compounds.

D. E. R. Hughes

\section{GENERAL ASTROPHYSICS}

\section{Astrophysique Générale}

Par J. C. Pecker et Prof. E. Schatzman. Pp. $x+756$. (Paris : Masson et Cie., 1959.) Broché, 12,000 francs ; cartonné toile, 13,000 francs.

A STROPHYSICS is not a big subject in relation to some other sciences, but in my view the day has passed when any complete and satisfactory account of it can be compressed into one text-book, unless at a quite elementary level. Here two wellknown French astrophysicists have attempted heroically to do the well-nigh impossible, and even if the result falls short of perfection it deserves a warm welcome, for good general text-books in this field are very scarce. We have on one hand a fair number of specialist monographs, some of them invaluable, and on the other more than enough glossy semipopular and popular books, most of which should be avoided as the plague by any serious student. Between these extremes there is remarkably little.

The first 100 pages of "Astrophysique Générale" are given over to a summary of "what every young astrophysicist should know"-everything from hydrodynamies to Hamiltonians, statistics to spectroscopy. It illustrates the wide range of technical knowledge a theoretical astrophysicist ideally should command, but is much too compressed to be anything but a refresher course for a recent honours graduate in mathematics or physies. A whole book written along these lines would be very useful, but I question the wisdom of attempting the task in less than, say, 1,000 pages. Part 2, dealing with astronomical instruments and methods of observation, is at a very different level of sophistication. It shows signs of having been written by theorists, for there are a number of over-simplified or over-optimistic statements (for example, "Pour les étoiles jaunes et rouges, la mesure des magnitudes radiométrique permet d'obtenu aisément les magnitudes bolométriques"), as well as a few small errors. In Part 3, the longest in the book, the authors are, however, more on their own ground, discussing what we know of stars, their spectra, masses, intrinsic luminosities, radii, and the theories of their atmospheres and their interiors. 